\title{
ANALISIS YURIDIS TENTANG TINDAK PIDANA PENCEMARAN NAMA BAIK MELALUI INTERNET DIKAITKAN DENGAN KEBEBASAN PERS
}

\author{
Oleh : \\ Rudolf Silaban ${ }^{1}$, \\ Jaminuddin Marbun ${ }^{2)}$ \\ Universitas Darma Agung, Medan., ${ }^{1,2}$ \\ E-mail: \\ banglabanshmh@gmail.com $^{1)}$ \\ jaminuddinmarbun@yahoo.co.id ${ }^{2)}$
}

\begin{abstract}
This study ims at finding out and understanding the provisions in the provisions of Indonesian law regarding the relation to defamation through the internet associated with press freedom, forms and criteria for criminal acts of defamation carried out in the internet media, forms of accountability for perpetrators of criminal defamation of names both through the internet in the applicable legal provisions in Indonesia. This research is a normative juridical research that is descriptive analytical and data analysis is carried out qualitatively descriptive, normative, logical, systematic, using deductive and inductive methods. The results of the study show that the regulation in the provisions of Indonesian law regarding the relation to defamation through the internet is related to freedom of the press. In a criminal case involving the press, of course, it cannot necessarily use the law against the law contained in the Criminal Code because a journalist's work is protected by Law No. 40 of 1999 concerning the Press. If there is a use of criminal legal instruments, then the element of unlawfulness contained in the Criminal Code must be linked to the Press Law. The forms and criteria for criminal defamation with complaints, insults to official bodies, insults to the dead. The forms of liability of perpetrators of criminal defamation through the internet in the provisions of applicable law in Indonesia, namely liability for criminal defamation through the internet media can be applied along with imprisonment sanctions or in the form of fines in accordance with applicable laws. This liability is charged in accordance with the criminal element which has been reviewed in terms of terms of criminal liability.
\end{abstract}

Keywords: Defamation, Internet, Press

\begin{abstract}
ABSTRAK
Tujuan Penelitian ini adalah untuk mengetahui dan memahami pengaturan dalam ketentuan hukum Indonesia tentang kaitan pencemaran nama baik melalui internet dikaitkan dengan kebebasan pers, bentuk-bentuk dan kriteria tindak pidana pencemaran nama baik yang dilakukan dalam media internet, bentuk-bentuk pertanggungjawaban pelaku tindak pidana pencemaran nama baik melalui internet dalam ketentuan hukum yang berlaku di Indonesia. Dalam penelitian hukum normatif, alat pengumpulan data yang dipergunakan melalui penelusuran dan atau studi kepustakaan agar memperoleh data sekunder yang diperlukan antara lain: Bahan hukum primer, yaitu bahan-bahan hukum yang mengikat, terdiri dari peraturan perundang-undangan yang berkaitan dengan pokok permasalahan.Bahan hukum sekunder, yaitu bahan yang memberikan penjelasan mengenai bahan hukum primer, berupa hasil penelitian para ahli, hasil-hasil karya ilmiah, buku-buku ilmiah, dan sebagainya.Bahan hukum tertier, yaitu bahan-bahan yang memberi petunjuk penjelasan terhadap bahan hukum primer dan sekunder, antara lain kamus hukum, kamus bahasa Indonesia, ensiklopedi dan lain
\end{abstract}


sebagainya.Hasil penelitian menujukkan bahwa Pengaturan dalam ketentuan hukum Indonesia tentang kaitan pencemaran nama baik melalui internet dikaitkan dengan kebebasan pers. Dalam kasus pidana yang melibatkan pers tentu saja tidak bisa serta merta pengadilan menggunakan unsur melawan hukum yang terdapat dalam KUHP. Karena pekerjaan seorang wartawan dilindungi oleh UU No. 40 Thn 1999 tentang Pers. Oleh karena itu, kalaupun ada penggunaan instrumen hukum pidana maka unsur melawan hukum yang terdapat dalam KUHP harus dihubungkan dengan UU Pers. Bentuk-bentuk dan kriteria tindak pidana pencemaran nama baik yang dengan pengaduan, penghinaan terhadap badan resmi, penghinaan terhadap orang mati. Bentuk-bentuk pertanggungjawaban pelaku tindak pidana pencemaran nama baik melalui internet dalam ketentuan hukum yang berlaku di Indonesia yaitu pertanggungjawaban tindak pidana pencemaran nama baik melalui media internet dapat diterapkan berikut dengan sanksi pidana penjara maupun berupa denda sesuai dengan ketentuan undang-undang yang berlaku. Pertanggungjawaban ini dibebankan sesuai dengan unsur pidana yang telah ditinjau dari segi syarat-syarat pertanggungjawaban pidana. Sehingga pelaku tindak pidana pencemaran nama baik, dapat mempertanggungjawabkan perbuatannya seperti yang telah diputuskan di pengadilan.

Kata Kunci: Tindak Pidana Pencemaran Nama Baik, Internet, Pers

\section{PENDAHULUAN}

Kejahatan pada hakikatnya merupakan proses sosial, sehingga politik kriminal (criminal policy) harus dilihat sebagai kerangka politik sosial (social policy) yakni usahamasyarakat untuk meningkatkan kesejahteraan warganya. Dengan demikian sistem peradilan pidana sebagai bagian mata rantai kebijakan pembangunan nasional harus mampu tampil sebagai social enginering (by criminal law) dalam rangka menjalankan fungsi kontrol sosial terhadap proses sosial.

Secara umum, ada banyak manfaat yang diperoleh apabila seseorang mempunyai akses ke internet. Dewasa ini, penggunaan internet telah merusak pada hampir semua aspek kehidupan, baik sosial, ekonomi, pendidikan, hiburan bahkan keagamaan Para akademisi merupakan salah satu pihak, yang paling diuntungkan dengan kemunculan internet. Aneka referensi, jurnal maupun hasil penelitian yang dipublikasikan melalui internet tersedia dalam jumlah yang berlimpah. Para mahasiswa tidak perlu lagi mengaduk-aduk buku di perpustakaan sebagai bahan untuk mengerjakan tugastugas kuliah. Sebagaimana diketahui Internet juga berperan penting dalam dunia ekonomi dan bisnis.

\section{TINJAUAN PUSTAKA}

Negara Hukum (Rule Of Law) yang dipelopori oleh A.V. Dicey, yang lahir dalam ruangan sistem hukum Anglo Saxon.A. V. Dicey mengemukakan unsurunsur Rule Of Law sebagai berikut:

1) Supremasi aturan-aturan hukum (Supremacy Of law), tidak adanya kekuasaan sewenang-wenang (Absence of Arbitrary Power), dalam arti bahwa seseorang hanya boleh dihukum jika melanggar hukum.

2) Kedudukan yang sama dalam menghadapi hukum (Equality Before The law). Dalil ini berlaku baik untuk orang biasa maupun untuk pejabat. 
3) Terjaminnya hak-hak asasi manusia oleh Undang-Undang di Negara lain oleh undang-undang dasar serta keputusan-keputusan pengadilan.Negara hukum pada dasarnya bertujuan untuk memberikan perlindungan hukum bagi rakyat.

Tidak dikenal peradilan administrasi negara dalam sistem Anglo Saxon. Dalam sistem Common Law, seperti Amerika Serikat dan Inggris, persoalan-persoalan administratif dihadapkan kepada pengadilan-pengadilan biasa (ordinary courts), dengan hakimhakim yang independen, untuk mempertahankan salah satu unsur terpenting dari the rule of law. the rule of law adalah mencegah penyalahgunaan kekuasaan diskresi. Pemerintah dilarang menggunakan privilege yang bertentangan dengan aturan hukum.

\section{Teori Perlindungan Hukum}

Hukum adalah untuk manusia, maka pelaksanaan hukum atau penegakan hukum harus memberikan manfaat atau kegunaan bagi masyarakat. Masyarakat sangat berkepentingan bahwa dalam pelaksanaan atau penegakan hukum, keadilan diperhatikan. Dalam

sistem Common Law, seperti Amerika Serikat dan Inggris, persoalan-persoalan administratif dihadapkan kepada pengadilan-pengadilan biasa (ordinary courts), dengan hakim-hakim yang independen, untuk mempertahankan salah satu unsur terpenting dari the rule of law.

\section{Teori Penegakan Hukum}

Memperhatikan dan membicarakan tentang tujuan pemidanaan, tidak lepas kaitannya dengan membicarakan teoriteori pemidanaan itu ialah:

1) Teori Absolut atau mutlak, yaitu setiap kejahatan harus diikuti dengan pidana, tidak boleh tidak dan tujuan hukuman adalah sebagai pembalasan dendam. Teori ini dikenal dan dianut sarjana seperti Immanuel Kant, Van Bemmelen, Van Hattum, dan Hegel.

2) Teori Relatif atau nisbi, yaitu yang mengatakan bahwa kejahatan tidak mutlak harus diikuti dengan suatu pidana, dimana tujuan penghukuman adalah agar kejahatan yang dilakukan itu tidak terulang lagi dan juga untuk memperbaiki si penjahat.

3) Teori Gabungan yaitu gabungan kedua teori di atas, penganutnya adalah Pompe, Hugo de Groot dan Rossi.

Seseorang terdakwa jika akan dipidana harus ternyata bahwa tindakan yang dilakukan itu bersifat melawan hukun dan terdakwa mampu bertanggungjawab. Menurut Roeslan Saleh, untuk adanya kesalahan yang mengakibatkan terdakwa (dipertanggung jawabankan), maka terdakwa haruslah:

1. Melakukan perbuatan pidana.

2. Mampu bertanggung jawab.

3. Dengan sengaja atau Alpa.

4. Tidak ada alasan pemaaf.

\section{Kerangka Konsep}

Berdasarkan judul Penelitian ini, Analisis Yuridis Tentang Tindak Pidana Pencemaran Nama Baik Yang 
Dilakukanmelalui Internet Dikaitkan Dengan Kebebasan Pers, dikemukakan hal-hal penting sebagai berikut:

a. Penyidikan adalahserangkaian tindakan penyelidik untuk mencari dan menemukan suatu peristiwa yang diduga sebagai tindakan pidana guna menentukan dapat atau tidaknya dilakukan penyidikan menurut cara yang diatur dalam undang-undang ini (Pasal 1 butir 5 UU Nomor 8 Tahun 1981 tentang KUHAP).

b. Tindak Pidana adalah perbuatan yang oleh aturan hukum dilarang dan diancam dengan pidana barang siapa yang melanggar larangan tersebut, selanjutnya beliau menyatakan menurut wujudnya atau sifatnya, tindak pidana itu adalah perbuatanperbuatan yang melawan hukum dan juga merugikan masyarakat dalam arti bertentangan dengan atau menghambat akan terlaksananya tata dalam pergaulan masyarakat yang dianggap baik dan adil.

\section{Keaslian Penelitian}

Penelitian yang berjudul Analisis Yuridistentang Tindak Pidana Pencemaran Nama Baik Yang Dilakukan Melalui Internet Dikaitkan Dengan Kebebasan Pers, sepanjang pengamatan peneliti belum pernah dilakukan di Universitas Darma Agung, hal ini berdasarkan informasi yang ada dan penelusuran kepustakaan, khususnya di lingkungan kepustakaan Universitas Darma Agung.Berdasarkan hal tersebut mengenai judul dan permasalahan yang ada dalam proposal penelitian ini, belum pernah diteliti oleh peneliti lain, dengan demikian penelitian ini asli, baik dari segi isi maupun dari objek penelitian sehingga penelitian ini dapat dipertanggungjawabkan.

\section{METODE PELAKSANAAN}

\section{Sifat Penelitian}

Penelitian ini merupakan penelitian yuridis normatif yang bersifat deskriptif analitis, yaitu penelitian yang bertujuan memberikan gambaran tentangpengaturan dalam ketentuan hukum Indonesia tentang kaitan pencemaran nama baik melalui internet dikaitkan dengan kebebasan pers,

\section{Teknik Pengumpulan Data}

Adapun metode pengumpulan data dalam penelitian ini ditempuh dengan cara Studi Empris/Lapangan.Menggunakan metode studi kepustakaan diperoleh asasasas, konsepsi-konsepsi, pandanganpandangan, doktrin-doktrin hukum serta isi kaidah hukum yang diperoleh dari dua referensi utama yaitu yang bersifat umum (perundang-undangan, peraturan, bukubuku teks, kamus) dan yang bersifat khusus (jurnal, laporan penelitian, dan lain-lain)

\section{Jenis dan Sumber Data}

Dalam penelitian hukum normatif, alat pengumpulan data yang dipergunakan melalui penelusuran dan atau studi kepustakaan agar memperoleh data sekunder yang diperlukan antara lain: Bahan hukum primer, Bahan hukum sekunder, Bahan hukum tertier.

\section{Lokasi Penelitian}

Penelitian ini dilakukan di Kepolisian Daerah (Polda) Sumatera Utara. 


\section{Analisis Data}

Analisis data dilakukan secara kualitatif deskriptif, normatif, logis, sistematis, dengan menggunakan metode deduktif dan induktif

\section{HASIL DAN PEMBAHASAN}

Tinjauan Umum Tentang Internet

\section{Sejarah Singkat Internet}

Cikal bakal dari internet adalah ARPANET, sebuah jaringan eksperimen milik pemerintahan Amerika Serikat berbasis komunikasi data paket yang didirikan ditahun 1969.

\section{a. Internet}

Internet adalah singkatan dari Interconnectio Network yang secara harfiah berarti hubungan antara janingan komputer (network). Network sendiri diartikan sebagai suatu sistem komunikasi data antar komputer

b. Fasilitas dan Manfaat Internet

Secara umum, ada banyak manfaat yang diperoleh apabila seseorang mempunyai akses ke internet. Internet juga berperan penting dalam dunia ekonomi dan bisnis

\section{Tindak Pidana Pencemaran Nama Baik} Melalui Internet

Sampai kini belum ada definisi hukum di Indonesia yang tepat tentang apa yang disebut pencemaran nama baik.

Tindak Pidana Pencemaran Nama Baik

Dikaitkan Dengan Kebebasan Pers

1. Pers dan Pencemaran Nama Baik Pers merupakan institusi sosial kemasyarakatan yang berfungsi sebagai media kontrol sosial, pembentukan opini dan media edukasi yang eksistensinya

dijamin berdasarkan konstitusi.

\section{Faktor Pemberitaan Yang Berakibat} Pencemaran Nama Baik

Menurut Mondary faktor penyebab dalam pemberitaan adalah: tidak akurat atau cermat, tidak lengkap, dan kronologis.

Tindak Pidana Pencemaran Nama Baik 1. Pengertian Umum Mengenai penghinaan dan Pencemaran Nama Baik

Sampai kini belum ada definisi hukum di indonesia yang tepat tentang apa yang disebut pencemaran nama baik. Selain itu, penghinaan dan pencemaran nama baik ini tidak jelas dan tidak ada ukurannya, siapa saja dapat masuk kedalam kategori ini.

\section{Pengertian Pencemaran Nama Baik}

Menurut Kitab Undang-undang

\section{Hukum Pidana}

Berdasarkan pemikiran bahwa penggunaan hak atau kewenangan perdefinisi harus merupakan suatu tindakan menurut hukum sehingga tidak dapat secara sekaligus juga menghasilkan suatu tindakan yang melanggar hukum .

3. Pengertian Pencemaran Nama Baik Menurut Undang-undang Informasi dan Transaksi Elektronik

Mahkamah Konstitusi menyatakan bahwaPasal-pasal tertentu dalam KUHP dianggap tidak cukup memadai untuk menjawab persoalan-persoalan hukum yang muncul akibat aktivitas dunia maya.

\section{Penyebab Pencemaran Nama Baik}

1. Penyebab Terjadinya Kejahatan (Etiologi Kriminal) 
Faktor penyebab (causes) diimplikasikan kapanpun istilah seperti menentukan (determine), mempengaruhi (influence), menghasilkan (produce), membentuk (shape), menimbulkan (generate), dan menyebabkan (effect) memasuki wacana teoritis.

Ide bahwa pendidikan menaikkan tingkat keterampilan dan tingkat upah yangkemudian menurunkan tingkat kejahatan, bukanlah hal yang baru. Ehrlich secaraempiris menguji sejumlah prrediksi dari sebuah intuitif model berkenaan denganpendidikan terhadap kejahatan

\section{Penyebab Terjadinya Tindak Pidana}

\section{Pencemaran Nama Baik}

Dalam hal pencemaran nama baik atau penghinaan, objek yang ingin dilindungi adalah kewajiban setiap orang untuk menghormati orang lain dari sudut kehormatannya dan nama baiknya dimata orang lain meskipun orang tersebut telah melakukan kejahatan yang berat

\section{Bentuk-Bentuk Pencemaran Nama Baik}

Salah satu perbuatan pidana yang sering mengundang perdebatan di tengah masyarakat adalahpencemaran nama baik. Dalam peraturan perundang-undangan di Indonesia, pencemaran nama baik (penghinaan) diatur dan dirumuskan dalam Pasal 310 KUHP. yang terdiri dari 3 (tiga) ayat.

\section{Penanggulangan Pencemaran Nama Baik Melalui Internet}

Sanksi dalam presfektif hukum pidana merupakan upaya represif terhadap suatu tindak pidana. Upaya represif adalah upaya untuk menanggulangi tindak pidana yang telah terjadi. Tujuan dari upaya represif adalah agar tindak pidana yang telah terjadi tidak terulang lagi di kemudian hari

\section{Pidana dan Pemidanaan}

\section{Pengertian Pidana}

Pembentuk undang-undang kita telah menggunakan istilah "tindak pidana" sebagai pengganti dari perkataan "strafbaar feit" tanpa memberikan sesuatu penjelasan mengenai apa sebenarnya yang dimaksud dengan perkataan "strafbaar feit" tersebut.

Pengertian dari tindak pidana adalah tindakan yang tidak hanya dirumuskan oleh Kitab Undang-undang Hukum Pidana (KUHP) sebagai kejahatan atau tindak pidana akan tetapi di dalamnya tidak memberi rincian tindak pidana tersebut.

\section{Tujuan Pemidanaan}

Kajian terhadap tujuan pemidanaan akan mengantarkan pada pemahaman tentang seberapa jauh sanksi pidana relevan dan karenanya patut dipertahankan dalam sistem hukum pidana

\section{Bentuk-Bentuk Pertanggungjawaban} Pidana Pencemaran Nama Baik Melalui Internet

Cyberlaw adalah Aspek hukum yang istilahnya berasal dari cyberspacelaw yang ruang lingkupnya meliputi setiap aspek yang berhubungan dengan orang perorangan atau subjek hukum yang menggunakan dan memanfaatkan teknologi internet yang dimulai pada saat mulai online dan memasuki cyberspace atau dunia maya.

\section{SIMPULAN}

Pengaturan dalam ketentuan hukum Indonesia tentang kaitan pencemaran nama 
baik melalui internet dikaitkan dengan kebebasan pers adalah dalam kasus pidana yang melibatkan pers tentu saja tidak bisa serta merta pengadilan menggunakan unsur melawan hukum yang terdapat dalam KUHP.

Bentuk-bentuk pertanggungjawaban pelaku tindak pidana pencemaran nama baik melalui internet dalam ketentuan hukum yang berlaku di Indonesia yaitu pertanggungjawaban tindak pidana pencemaran nama baik

\section{DAFTAR PUSTAKA}

Buku

Abdullah, Aceng, Pers Relation Kiat-Kiat Berhubungan Dengan Pers, PT Remaja Rosdakarya, Bandung, 2000.

Anwar, Yesmil \& Adang, Pembaharuan Hukum Pidana, Grasindo, Jakarta, 2008

Arief Sidharta, B., 1999, Refleksi Tentang Struktur Ilmu Hukum (Sebuah Penelitian Tentang Fundasi Kefilsafatan dan Sifat Keilmuan Ilmu Hukum Sebagai Landasan Pengembangan Ilmu Hukum Nasional Indonesia),Mandar Maju.,Bandung.

Asmarawati, Tina, Hukum dan Psikiatri, Deepublish, Yogyakarta, 2013.

Bassar, Soedrajat, Tindak-tindak Pidana Tertentu, Ghalian, Bandung, 1999.

Chazasi, Adami,Stelsel Pidana, Tindak Pidana, Teori-teori Pemidanaan dan Batas Berlakunya Hukum Pidana, Raja Grafindo Persada, Jakarta, 2008.
DiCristina, Bruce, Method in criminology:

A Philosophical Primer, Harrow and Heston, New York, 1995.

Dirdjosisworo,Soedjono,Filsafat

Peradilan Pidana dan Perbandingan Hukum, Armico, Bandung, 1984.

\section{B. Perundang-Undangan}

Republik Indonesia, Undang-Undang Dasar 1945.

Undang Nomor 19 Tahun 2016 tentang ITE.

Undang Nomor 40 Tahun 1999.

Undang-

-----------------------, Kitab Undang-

Undang Hukum Pidana.

C. Internet

Anwariansyah, Menyoal Amandemen Pasal Penghinaan dan Pencemaran Nama Baik, www.wikimu.com.

Badan Informasi dan Komunikasi, Upaya Polri Dalam Menangani Kasus-kasus Cybercrime, http://FokomSumut.Go.id.

http://repository.usu.ac.id/bitstream/12 3456789/17931/3/chapter\%201 1.pdf.

http://www.freewebs.com, Panduan Internet Untuk Pemula.

http://www.romeltea.com/2010/02/02 delik-delik pers. 